Edmur Arnaldo Chieregatto, Heloísa Helena Ferreira dos Santos, Lucila Kneese Flaks e Silvia Loretta Lakeland *

\title{
O Setor Bancário Brasileiro: uma Análise Sistêmica
}

Adotando a abordagem mais moderna de análise de organizações - a teoria de sistemas - elaboramos um estudo do setor bancário brasileiro. Através dêsse estudo procuramos diagnosticar o estágio atual em que se encontram os bancos, analisando as variáveis dêsse processo. Procuramos também projetar, no tempo, a linha de evolução que aquêle setor deverá seguir.

Consideramos como universo de nossa análise os 50 maiores bancos privados nacionais, ${ }^{2}$ dos quais escolhemos, aleatòriamente, 10 .

A coleta de informacões foi feita por meio de entrevistas de profundidade, em nível de gerentes de departamentos e direção-geral.

Agradecemos aos bancos que conosco colaboraram e cujos nomes deixamos de citar por razões éticas e atendendo sua solicitação.

\section{TEORIA DE SISTEMAS}

Pelo enfoque sistêmico, consideramos a organização um sistema aberto, que está em constante interacão com - ambiente externo, através de um processo de troca (importação e exportação) de informaçōes e energia.

Pela sua característica básica de interação com o ambiente externo, a organização absorve energia que alimentará suas atividades dirigidas àquele ambiente.

Esta organização será um sistema aberto, pois uma certa quantidade de energia/entropia ' tenderá a ser negativa, o que permitirá a sobrevivência e a expansão.
A energia captada do ambiente externo através do insumo informativo é transformada pela organização e convertida em produto para o ambiente. Essa troca de energia tem caráter cíclico, permitindo continuidade das atividades conseqüentes da interação organização/ambiente externo.

Ao mesmo tempo, o feedback (retroalimentacão), transforma-se em insumo informativo, através de um processo de codificação que permite corrigir eventuais desvios do produto organizacional.

Para impedir o processo entrópico, a organização precisa manter um "estado estável", mas, ao mesmo tempo, um "equilíbrio" dinâmico.

0 equilíbrio existirá enquanto o caráter do sistema fốr mantido, ao mesmo tempo em que ocorrerem modificacões nas suas características estruturais, ou seja, o comportamento dos fenômenos do sistema não se repetem jamais ou retornam ao ponto inicial como por exemplo, o giro de uma espiral.

* Alunos do curso de pós-graduacão da Escola de Administracão de Emprêsas de São Paulo, da Fundaçáo Getálio Vargas.

1 Como ganhar dinheiro: sorte ou talento? Visăo, p. 125, 25 abr. 1970: Para onde vai o mercado de dinheiro? Visão, p. 117-18, 29 mar. 197

2 "O processo entropico é uma lei universal da natureza, no qual tódas as formas de organizaçáo se movem para a desorganizaçåo ou morte." Ver Katz, D. \& cres. Atias, 1970. p. 37. 
O dinamismo que permite mudanças e expansões é de natureza homeostática, isto é, de preservação do caráter do sistema através do crescimento e da expansão. No setor bancário, por exemplo, o caráter não se modificou, e tende mesmo a se manter, apesar de tôdas as mudancas e expansões ocorridas. Isto é, os giros da espiral permitiram evolução dinâmica, mantendo sempre um estado estável.

Como conseqüência da entropia negativa, os sistemas abertos tendem a uma crescente diferenciacãn. traduzida pela multiplicacão de napéis e especialização de funçōes.

Um sistema aberto pode atingir o mesmo produto, partindo de diferentes condicões e diferentes processamentos. Este é o princípio da eqülifinalidade dos sistemas abertos e que apresenta mecanismos regulatórios para controlar suas operaçōes.

Ao contrário dos sistemas mecânicos e biológicos. os abertos têm a propriedade de se modificarem na sua estrutura básica. Esta propriedade é chamada morfooênica. segundo designação de Buckley. "

Como todo sistema social. os sistemas abertos apresentam subdivisర్es chamadas subsistemas, que são bàsicamente:

de producão - relacionado com a transformação e processamento do insumo de energia e Informacão e cuio ciclo de atividade compóe as principais funcões do sistema: comparando com a organizacão tradicional, corresponderia aos setores de linha de montagem, transformação de matéria. prima, etc.

de manutenção - que garante a disponibilidade de energia humana cujo desempenho padronizado resulta no funcionamento da emprêsa. Caso típico do departamento de pessoal. embora dificilmente as funções do sistema de manutencão possam ser totalmente preenchidas por um departamento.

de apoio - que diz respeito aos intercâmbios transacionais com o ambiente, em grande parte unidirecional vendo a manipulacão do ambiente de um tipo especifico e focalizado. Como os departamentos de compras e vendas, setor de relações públicas, entre outros.

de adaptação - perscruta o ambiente externo à procura de elementos que se traduzem em mudanças para a organização que assim assegurará sua sobrevivência e expansão. Corresponde aos setores de pesquisa, planejamento, desenvolvimento de novos produtos e outros. gerencial - engloba a direção, coordenação, contrôle e adaptação dos outros subsistemas e unidades produtivas da organização ao ambiente, tes: público em geral, comercial, industrial, rural e o institucional, representado pelo Govêrno como elemento regulador.

Esquema representativo da organizaģo como um sistema

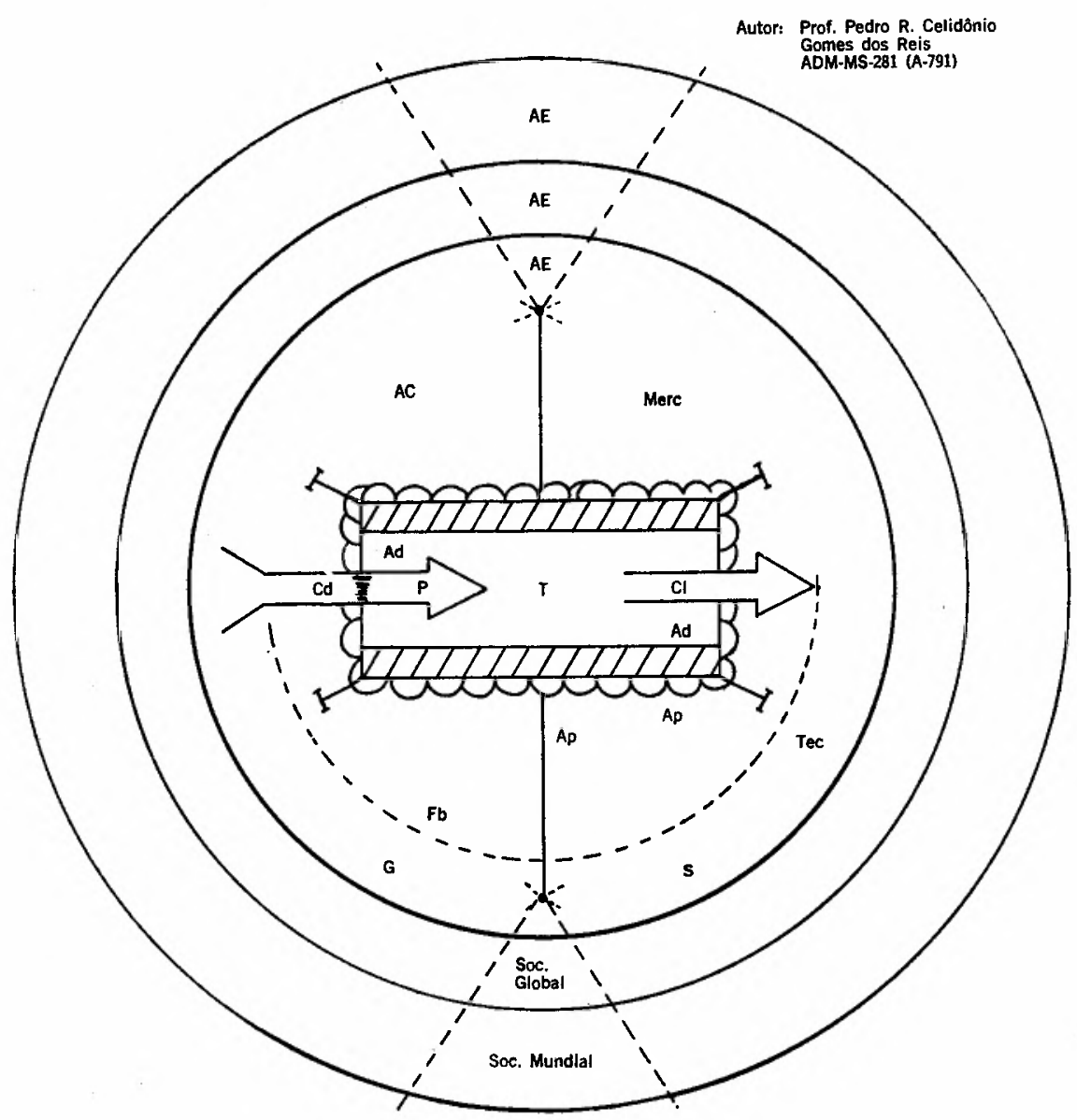

ESTRUTURA - SUBSISTEMAS

\begin{tabular}{|c|c|c|c|}
\hline T - Técnicá (Produçăo) & 1 & - Institucional & $A E$ - Ambiente Externo \\
\hline $\mathrm{Cl}$ - Colocaçăo & Ap & - Adaptativo & cd - Codificaçâ \\
\hline P - Procura & Ad & - Administrativo & AC - Associagăo de Classe \\
\hline M - Manutençăo & $F b$ & - Feedback & - Sindlcatos \\
\hline G - Governo & Mer & - Mercado & Tec - Tecnologia \\
\hline
\end{tabular}

abrangendo todos os níveis do sistema global, apresentando-se sob forma de mecanismos regulatórios e de estruturas de autoridade, ou seja, a estrutura hierárquica.

de colocação - conseqüência de tôdas as atividades concatenadas dos outros subsistemas da organização. Êste subsistema será mais eficiente à medida que satisfizer as expectativas do ambiente externo, dentro de uma utilização global dos esforços e recursos da emprêsa.

\section{AMBIENTE EXTERNO}

A ação do setor bancário volta-se essencialmente para os subambien-
0 ambiente externo apresenta-se padronizado para o setor, na medida em que os bancos, na sua maioria, através de rêde nacional de agências atingem os diversos subambientes, com características e problemas específicos correspondentes a cada região.

- "A maximização da entropia em um sistema fechado tende a minimizar as diferenças entre as partes e tende, portanto, a maximizar a desorganizaçăo entre as partes do sistema." Ver Bertalanffy, $L$ von. General system theory In Demerath, N. J. \& Peterson, R. A. System, change and conflict. New York. The Free Press, 1967. p. 115-30.

L Lawrence, Paul R. \& Lorsch, Jay W. Developing organizations: diagnosis and action. Reading, Mass.. Addison Wesley Sublishing Co. 1969. P. 10. Buckley, Walter Englewood Cliffs. N. J., Prentice-Hall, 1.967 . 
Por outro lado, o Govêrno, como elemento normativo, age uniformemente em todo o setor bancário, atuando como principal fator e provocando uma necessidade de mudança nos bancos.

Essa mudança foi conseqüência direta da Lei n.० 4.595 de 31 de dezembro de 1964, que estruturou o sistema financeiro nacional, estabelecendo normas reguladoras do setor e definindo suas características principais, instituições componentes e áreas de especifficas de ação."

Com a extinção da Superintendência da Moeda e Crédito (SUMOC) coube ao recém-criado Banco Central a execucão e físcalizacão das normas instituídas. Em seguida, surgiu o Conselho Monetário Nacional com o objetivo precípuo de elaborar a política monetária e creditícia nacional."

A regulamentação trazida pelas leis serviu como insumo de informacão para o sistema bancário, gerando a energia necessária para a sobrevivência e expansão do setor.

Esse insumo transformado em energia agiu. e continua agindo, combulsóriamente, como fator de adequacão do sistema bancário às necessidades prementes do ambiente externo. Com isso, o estado homeostático é mantido através da interacão constante e dentro de condição estável.

\section{INTERACAO SETOR BANCARIO/ AMBIENTE EXTERNO}

Definimos dois niveis de interação. Inicialmente, o setor bancário com o subambiente institucional. Desta interacão conscientizaram-se os problemas de custos operacionais.

Os níveis da taxa de depósitos compulsórios. da taxa de redescontos, a reducão da taxa de juros e a política de open market impuseram aos bancos uma situacão compressiva. O primeiro reflexo foi a urgência de redução dos custos operacionais. De um modo geral, agências deficitárias ou pouco lucrativas foram liquidadas ou substituídas.

Criou-se a necessidade de um quadro de pessoal especializado, mais eficiente e técnico, para atender as atividades de um banco moderno.

Assim foi possível criar uma infra-estrutura organizacional, cuja interação com 0 ambiente externo foi um resultado positivo, tanto em relacão à política antiinflacionária do Govêrno quanto ao provocar uma diversificação para atender às necessidades do mercado.

Numa primeira fase, alguns bancos que nåo atenderam às exigências numa velocidade satisfatória - fundiram-se ou foram encampados.

Esses processos de fusão e encampação verificam-se ainda, e com certa freqüência, como conseqüência de uma constante necessidade de adequação às contínuas exigências do ambiente extemo.

Em consequiência dêsses fatôres e da dificuldade imposta pelo Govêmo para a obtenção de cartas patentes e pela política de incentivos para instalação de agências em praças em que a assistência financeira era reduzida, diminuíram em número as matrizes, e o número de agências aumentou.

Essa explicação pode ser demonstrada pelo fato de que, em 1957, havia 4.628 agências para 357 matrizes. Em abril de 1967, era de 7.026 agências para 272 matrizes.? No fim de 1970 , o número de matrizes era de 195 . $^{\text {. }}$

Ao mesmo tempo, os bancos, cada vez mais competitivos e visando a atingir a nova modalidade de crédito, tiveram autorizacăo para criar companhias de crédito, financiamento e investimento. Através destas e utilizando a nova sistemática, conseguiram captar depósitos a médio e longo prazo adequando-se assim à demanda de crédito dentro daqueles periodos.

Este é o início do segundo nivel de interação, já voltado para as necessidades do mercado.

Procurando ambliar as áreas de servicos prestados aos subambientes - público, comercial, industrial e rural - o setor bancário dinamizou seu processo de diversificacão criando e incrementando seus subsistemas, voltados para cada subambiente.

Assim, por exemplo, na área de operacões específicas, os bancos apresentaram programas de crédito rural, industrial, leasing, cheques de viagem, sistemas organizados de cobranca e recebimento de impostos, taxas e contas em geral, etc.

\section{OS SUBSISTEMAS}

0 que pudemos constatar nos bancos analisados é que há uma defasagem entre os vários subsistemas. Por outro lado, encontramos um setor de processamento de dados extremamente desenvolvido, enquanto setores como comercializacão, propaganda e pesquisa, são incipientes.

Uma das principais razões que poderiam justificar essa defasagem é a situação de transição em que se encontram atualmente os bancos.

Após uma primeira fase normativa, hoje os bancos, já com um esbóço de estrutura, começaram a voltar-se para um desenvolvimento mais intensivo, procurando eliminar as distorções ainda existentes.

\section{O subsistema de produção, que} transforma informacão e energia e cujos ciclos de atividades compõem as principais funções do sistema, compreende, no setor bancário, tốdas as operações de manipulação e transformação do seu principal produto, ou seja, a moeda.

Êsse subsistema engloba o setor de processamento de dados - nos bancos já mecanizados - e o pessoal em nível hierárquico inferior ao de gerente.

O setor de processamento de dados, extremamente desenvolvido na maioria dos bancos analisados, evidencia uma acentuada defasagem no tratamento da informação, na medida em que admitimos a necessidade de uma combinação equilibrada da relação homem/máquina. Por um lado, uma crescente sofisticacão dos equipamentos eletrônicos introduzidos nos diversos setores. Mas, por outro lado não existe ainda uma conscientização da necessidade de combinar elementos de alto nível de aualificação a essas máquinas sofisticadas.

De fato, observamos um primarismo excessivo nos programas utilizados e um abroveitamento muito baixo da capacidade das máquinas.

A defasagem observada entre o setor de processamento de dados (subsistema de producão) e o setor de organizacão e métodos e de pessoal (manutenção) não é a única que pudemos notar.

O subsistema de manutenção. voltado para o interior da organizaçã̃o, compreende atividades como selecão, recrutamento, treinamento de pessoal organizacão e métodos, atividades essas defasadas no seu desenvolvimento harmonioso com relacão ao sistema organizacional. Por exemplo, onde na maioria dos bancos encontramos uma acentuada sofisticacão do tratamento da informacão - através de computadores eletrônicos - encontramos setores de pessoal incipientes, com problemas humanos agravados por uma falta de estrutura formal e/ou funcional.

Com raras excecões, encontramos uma organização realmente formalizada em têrmos de organogramas, regulamentos e normas internas, descrição de funcōes e racionalização de trabalho.

Se dentro do próprio subsistema de manutenção encontramos defasagens, essas são mais acentuadas entre êsse e os outros subsistemas.

Ribeiro. Benedito \& Guimarăes, Mário Mazzei. História dos bancos e do desenvolvimento financeiro do Brasit. Pro-Service Ltda., 1967. p. 179.

Relat6rio de 1967 do Banco do Brasị S. A. p. 175 .

7 Ribeiro, Benedito \& Gulmarăes, Mário Mazzei. op. cit. p. 127.

\& Relatório da Diretoria, Exercício de 1970 não cịtamos o nome do banco por razōes éticas. 
De fato, o subsistema de adaptação, voltado para o mundo exterior, visa a conseguir a consistência do ambiente, procurando estender as fronteiras da organização. ${ }^{\circ}$

O subsistema adaptativo é o responsável direto pela captação dos insumos de informação, que revelam as necessidades do ambiente externo. $E$, procurando essas informaçōes, juntamente com os outros subsistemas, apresenta as recomendações para as mudanças. ${ }^{10}$

Para captar as novas necessidades do mercado - processo de transformação morfogênica ${ }^{11}$ — os bancos instituiram o subsistema adaptativo, pràticamente inexistente até 1964.

Compreendendo as áreas de pesquisa, planejamento, expansão, propaganda, etc., a função de adaptação tem sido responsável pela sobrevivência dos bancos brasileiros, bem como geradora da dinâmica da evolução dêsses bancos, além de aumentar seu poder competitivo.

Até 1970, a maioria dos bancos voltava-se à consolidação de sua infra-estrutura. Uma vez confirmado o estado estável (manutenção), os bancos visualizaram a necessidade do processo homeostático, ou seja, mudanças freqüentes e constantes de diversificação.

Dentro desta concepçăo, em 1970 , criaram-se os setores de marketing, que englobam - em todos os bancos - as funçōes adaptativas.

Até o presente momento não incluímos, na análise dos diversos subsistemas, considerações sôbre o setor orçamentário, pois, tornou-se difícil identificar a qual subsistema corresponderia êste setor.

Podemos dizer que é uma das áreas mais recentes no sistema global bancário para o qual a maioria dos bancos está convergindo seus interêsses.

Se até agora encontramos um sistema orçamentário extremamente frágil, percebe-se hoje uma conscientização da necessidade de contrôle dos budgets em têrmos de distribuição mais eficiente com conseqüente redução dos custos operacionais.

O subsistema institucional, que visa à obtenção do apoio social e legitimacão das mudanças, compreendeu nos bancos até 1964 - organizações na sua maioria familiares - a alta direção dêsses bancos. A partir dêsse ano, conscientes da verdadeira estrutura organizacional necessária, em um mercado em constante evolução, criaram-se sistemas institucionais em diliversos niveis: por um lado, a alta direção (também representada pelo conselho de administração), responsável pelas grandes diretrizes da organizaçăo; por outro lado, em nível imediatamente inferior, setores de relações públicas, voltados para a transmissão e captação de informacões que se vão constituir no principal feedback do nosso sistema bancário.

Finalmente, destacamos o setor gerencial como aquêle que cruza tôdas as estruturas organizacionais de produção, manutenção, de apoio do ambiente e de adaptação. ${ }^{19}$

Com as funções básicas de coordenação das subestruturas, de manipulação dos conflitos entre os níveis hierárquicos e coordenação dos requisitos externos com os recursos e necessidades organizacionais, ${ }^{18}$ encontramos no setor bancário, o sistema gerencial altamente desenvolvido. Apesar da constatação de uma grande defasagem entre os diversos subsistemas e dentro dêles, coube ao subsistema gerencial, representado pelo alto escalão hierárquico, dar 0 grande impulso que podemos verificar nos bancos atuais, através de uma coordenacão e nivelação dos problemas organizacionais e de sua ação no ambiente externo.

Até recentemente. ainda dentro de uma filosofia de crescimento vegetativo. o setor bancário permaneceu voltado para si mesmo. não enfatizando devidamente o subsistema de colocacão. A partir de entăo, muito lentamente, inverteu-se o enfoque, na medida em aue os bancos iniciaram um processo de melhoria na prestacão e colocação de servicos e, finalmente, nesses últimos dois anos uma tendência à diferenciacão de servicos prestados e na maneira de serem colocados.

Convém notar que houve uma conscientização extremamente lenta das necessidades de atender a um mercado cada vez mais exigente, assim como de vencer uma crescente concorrência no setor.

Podemos dizer que o banco que mais ràpidamente aperfeiçoar seu subsistema de colocacão estabelecerá uma posição mais firme e certamente de liderança.

Como em todo sistema aberto, podemos observar, no setor bancário, um dos princípios fundamentais. a equilfinalidade sistêmica. Ou seja, a partir de condicões iniclais diferentes, $e$ através de diferentes maneiras. 0 mesmo estado final pode ser obtido. ${ }^{14}$ De fato, apesar de partirem de estruturas diferentes, com defasagens entre seus subsistemas. os bancos atingiram os mesmos objetivos, 0 mesmo estado final, ou seja, uma maior diferenciação de serviços para atingir uma maior faixa do mercado, dentro das normas instituidas pelo sistema financeiro nacional.

\section{TENDENCIAS PROVAVEIS}

\subsection{Comportamento do mercado}

Seriam as principais variáveis a afetar mais diretamente o setor bancário: tendências de aumento da renda per capita, com conseqüente aumento do padrão de consumo, aumento da poupança, dos investimentos, tendência a um maior nivelamento entre as diversas regióes do país e desenvolvimento dos centros urbanos.

Isto é, o mercado potencialmente maior e cada vez mais exigente e sofisticado, particularmente permeável às modificaçōes inovadoras.

\subsection{0 setor bancário voltado para o mercado}

Uma crescente auto-afirmação através de um desenvolvimento dos setores de pessoal, projetados em nivel de seleção - pessoal mais qualificado, treinamento, tanto para os novos quanto para os elementos já existentes na emprêsa, - nos vários níveis, para execução mais eficiente das tarefas e uma integração indivíduol emprêsa cada vez maíor.

A preocupação da reducão dos custos operacionais e racionalização do trabalho ainda persistirá como fator de crescimento organizacional do setor.

o setor de organização e métodos deverá afirmar-se em têrmos de formalizacão das estruturas hierárquicas; os níveis de conflito deverão ser identificados, estabelecidos e manipulados.

Em têrmos de sistemas e métodos, o tratamento da informacão tenderá a ser integrado, com relacão aos diversos subsistemas e os equipamentos eletrônicos tenderão a um melhor aproveitamento através de crescente racionalizaçăo.

Como já destacamos anteriormente, é problemática a interação homem/ máquina no setor bancário.

Uma otimizacão no uso dos computadores eletrônicos sòmente será viável eliminando-se as atuais distorções entre o nivel sofisticado dos equipamentos e o primarismo dos técnicos que os manipulam.

Caberá ao setor bancário conscientizar-se rápidamente dêste problema, procurando resolver êsse conflito através de maior eficiência nos setores

\footnotetext{
- Katz, D. \& Kahn, R. op. cit. p. 113.

10 Katz, D. \& Kahn, R. op. cit. p. 107.

11 "Aos processos de transformação que visam a aumentar a ordem e a organizaça das partes dos sistemas abertos, inciusive entre elas mesmas, pode-se dar o nome de morfogênese." Buckley, $w$. op. cit.

12 Katz, D. \& Kahn, R. op. cit. p. 116-17.

18 Katz, D. \& Kahn, R. op. cit: p. 107.

14 Berlinck, Manoel T. Populaçăo, centralidade relativa e morfogênese sistêmica em areas urbanas do Estado de Sao Paulo. Revista de Administraçăo de Em-
} presas, (29), 1968 
de organização e de sistemas e métodos. Vale como sugestão cursos de treinamento nos diversos niveis e um esquema de seleção mais rigoroso e técnico dos vários elementos envolvidos.

Por outro lado, a crescente tendência de nítida separação dos diversos subsistemas levará necessàriamente a uma definição mais clara das funções e, portanto, o pessoal deverá corresponder às novas exigências com maior qualificação técnica e profissional. De fato, já é notório o desenvolvimento do papel do gerente de agência que, longe de ser aquêle elemento primário de outrora, hoje é cada vez mais solicitado e deve estar à altura do seu cargo. Confirmando nossa análise, podemos verificar as citações feitas no último Congresso Nacional de Bancos, pelo Professor Theophilo de Azeredo Santos, Presidente do Sindicato de Bancos da Guanabara, no qual enfatiza o papel do gerente afirmando: "o gerente, no qual repousa a maior parcela do êxito de uma agência, já não é hoje um mero descontador de notas promissórias e duplicatas. Hoje o seu cargo reclama conhecimentos variados: compra e venda de ações, debêntures, (...) e outros encargos". "'

O subsistema adaptativo, através de um aumento do processo de informaçăo, na medida em que o setor de pesquisas - insumo informativo - e os setores de propaganda e relações públicas - produto informativo desenvolverem-se, tenderá a uma condição mais favorável para a absorção de inovações $e$, portanto, uma diferenciação de serviços, voltando-se inclusive aos "conglomerados de serviços", ${ }^{10}$ ou seja, uma diferenciação de atividades, não apenas financeiras.

Consequientemente, o potencial competitivo será tanto maior quanto maior fôr a sua capacidade de captação - transformação e manipulação das informações, de adaptação de acôrdo com a informação, da perfeita integração do produto processado. A tendência de redução do número de matrizes, mediante fusões e encampações, deverá continuar por algum tempo, assim como as agências deverão aumentar em número, cobrindo maiores áreas do país.

O subsistema gerencial, atualmente concentrado no alto escalão hierárquico da organização, tenderá a uma distribuição por áreas especializadas, em níveis hierárquicos imediatamente inferiores, com o mesmo ou até maior eficiência de resultados. 0 administrador profissional será definitivamente incorporado ao setor bancário o qual absorverá especialistas de várias áreas.

Atualmente centralizado, na maioria dos casos, pelo grupo familiar, o subsistema gerencial deverá despersonalizar-se através da introdução de elementos qualificados dentro da organização e conseqüente expansão das fronteiras operacionais da emprêsa.

Constatamos, através desta análise sistêmica, uma distorção dos vários subsistemas, embora tenham permitido a sobrevivência do sistema pelo bom senso e pela experiência do subsistema gerencial.

Acreditamos que uma redistribuição dos pesos, nos vários setores que compreendem a organização bancária liberará a estrutura gerencial para tomadas de decisão em níveis mais elevados, com reflexos em mercados mais importantes, deixando as responsabilidades de nível operacional aos setores que the competem.

\section{REFERENCIAS BIBLIOGRAFICAS}

Bennis, Warren. Organization development: its nature, origins and prospects. Addison Wasley Publishing Co., Reading, Mass., 1969.

Bertalanffy, Ludwing von. General system theory. In: Demerath, N. J., \& Peterson, R. A., System, change and conflict. New York, The Free Press, 1967.

Buckley, Walter. Sociology and modern system theory. Englewood Cliffs, N. J., Prentice-Hall, 1967.

Katz, Daniel \& Kahn, Robert L Psicologia social das organizaçôes. S. Paulo, Editôra Atlas, 1970.

Lawrence, Paul R. \& Lorsch, Jay W. Developing organizations: diagnosis and action. Reading, Mass., Addison Wesley Publishing Co., 1969.

Ribeiro, Benedito \& Guimarães, Mário Mazzei. História dos bancos e do desenvolvimento financeiro do Brasil. Pro-Serviçe Ltda., 1967.

Thompson, Victor. Bureaucracy and innovation, 1968.

Wiener, Norbert. Cibernética e a sociedade - o uso humano dos sêres humanos. São Paulo, Editôra Cultrix, 1968.

Revista de Administração de Emprêsas:

Berlinck, Manoel Tosta. População, centralidade relativa e morfogênese sistêmica em áreas urbanas do estado de São Pauto. Revista de Aministração de Emprêsas, 8 (29), dez. 1968.

Lodi, João Bosco. A estrutura matricia e a estrutura sistêmica: dois novos tipos de organização. Revista de Administração de Emprêsas, 10 (3), dez. 1970.

Motta, Fernando C. Prestes. A teoria geral dos sistemas na teoria das organizações. Revista de Administração de Emprêsas, 11 (1), mar. 1971.

Como ganhar dinheiro: sorte ou talento? Visăo, 25-5-70.
Para onde vai o mercado de dinheiro? Visão, 29-3-71.

Lélio explica superavit Banespa. Banas, n.० 826, 16-2-70.

Capital estrangeiro nas financeiras: nada além de $30 \%$. Banas, n. ${ }^{\circ} 840$, 25-5-70.

Um banco de avô para neto. Banas, n. ${ }^{\circ}$ 847, 13-7-70.

Bonfiglioli caçador de dividendos.

Banas, n. ${ }^{\circ} 848,20-7-70$.

A Caixa é forte. Quem duvida? Banas, n.० $872 / 73,4 / 11-2-71$.

Um sôco no queixo do pessimismo. Banas, n. ${ }^{\circ} 874,18-1-71$.

BAESP atua em tôdas as direções. Banas, n..$^{878, ~ 15-2-71 . ~}$

Um banco que já nasce grande. Banas, n. 881, 8-3-71.

Para ser banqueiro é preciso algo mais. Banas, n. ${ }^{\circ} 882$, 15/22-3-71.

Banespa tem fôrça em São Paulo. Banas, n.॰ 883, 29-3-71.

Sistema bancário na Alemanha. Banas, n. ${ }^{\circ} 884$, mar. 1971.

Homens no banco no Banespa. Banas, n. 885, 5-4-71.

Êsse médico faz transplantes bancários. Banas, n. ${ }^{\circ} 887,19-4-71$.

Delfim e os banqueiros. Banas, $n .^{\circ} 888$, 26-4-71.

Dose certa para desenvolver. Banas. n. ${ }^{\circ} 891,7-6-71$.

Crescendo como poucas agências. Banas, n.0 894, 7-6-71.

Brasil financeiro 1970-1971. Banas Financeiro, $70 / 71$.

Bancos debatem seu futuro. Mundo Econômico, 4 (4), abr. 1971.

VIII Congresso Nacional de Bancos. p. 20-25.

15 Bancos debatem seu futuro. Mundo Econ8mico, 4 (4): 20-25, abr. 1971.

16 Criamos êsse têrmo para definir o conjunto de diferentes serviços prestados pelos bancos em geral tais como: financiamentos, turismo, cartăo de crédito, cartőes de desconto automático, servicos de cobranca $e$ recebimento de taxas e impostos, etc. O "conglomerado de serviços" centraliza uma série de atividades financeiras do público em geral e dos outros subambientes. 